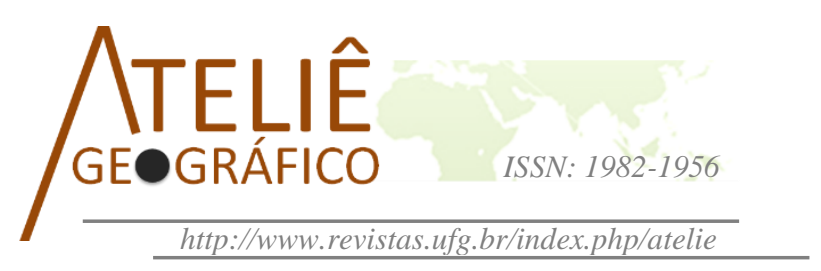

\title{
O uso de jogos por professores de Geografia na Educação Básica
}

\author{
The use of games by Geography teachers in basic education \\ L'utilisation de jeux pour les enseignants de Géographie \\ dans l'éducation de base
}

\author{
Tais Pires de Oliveira \\ Universidade Estadual de Maringá \\ tais_piresoliveira@hotmail.com \\ Claudivan Sanches Lopes \\ Universidade Estadual de Maringá \\ claudivanlopes@gmail.com
}

\begin{abstract}
Resumo
Este artigo apresenta resultados de pesquisa cujo objetivo foi discutir, no contexto das didáticas específicas, a utilização de jogos como recurso didático por professores de Geografia no processo de ensino-aprendizagem. A metodologia adotada para a realização do trabalho privilegiou os aspectos qualitativos, sem desconsiderar os dados quantitativos, embasando-se em aportes teóricos que discutem a temática contemplada. Para atingir o objetivo, a coleta de dados foi desenvolvida junto aos professores de Geografia do Núcleo Regional de Educação de Maringá - NRE/SEED - Paraná e realizada em dois momentos: o primeiro a aplicação de questionários e o segundo a realização de entrevistas semiestruturadas. Essas informações foram tabuladas e analisadas considerando a metodologia da análise de conteúdo e da bibliografia estudada. As discussões ora abordadas revelam que o emprego dos jogos no processo de ensino e aprendizagem de Geografia é recorrente e leva a refletir se os materiais empregados, tipologias e finalidades, possibilitam que o aluno desenvolva e exercite significativamente modos de pensar próprios da ciência geográfica.
\end{abstract}

Palavras-chave: Didática da Geografia; Ensino de Geografia; Jogos geográficos.

\begin{abstract}
This article had as a result the challenge of the exercise, in the context of specific didactics, the use of games as didactic resource by teachers of Geography in the teaching-learning process. The methodology adopted for carrying out the work focused on the qualitative aspects, without disregarding the quantitative data, based on theoretical contributions that discuss the subject matter. In order to reach the objective, the data collection was developed with the teachers of Geography of the
\end{abstract}


Núcleo Regional de Educação de Maringá - NRE/SEED - Paraná and performed in two moments: the first was the application of questionnaires and the second was the realization of semi-structured interviews. This information was tabulated and analyzed based on the methodology of content analysis and the bibliography studied. The present discussion reveals that the use of games in the teaching-learning process of Geography is recurrent and leads to reflect if the materials used, typologies and purposes, allow the student to develop and exercise significantly modes of thinking specific to geography.

Keywords: Geography Didactic; Geography Teaching; Geographic games.

\begin{abstract}
Résumé
Cet article présente des résultats de recherche dont l'objectif était de discuter, dans le cadre de didactiques spécifiques, l'utilisation des jeux comme ressource didactique par les enseignants de géographie dans le processus enseignement-apprentissage.

La méthodologie adoptée pour mener à bien le travail s'est concentrée sur les aspects qualitatifs, sans négliger les données quantitatives, basées sur des contributions théoriques qui traitent du sujet. Pour atteindre l'objectif, la collecte de données ce développé avec des enseignants de Géographie du Núcleo Regional de Educação de Maringá - NRE / SEED - Paraná et réalisé en deux moments: le premier était l'application de questionnaires et le second était la réalisation d'entretiens semistructurés. Cette information a été tablée et analysée en fonction de la méthodologie de l'analyse de contenu et de la bibliographie étudiée. Les maintenant des discussions renfermaient révèlent que l'utilisation des jeux dans le processus d'enseignement apprentissage de la Géographie est récurrente et conduit à examiner si les matériaux utilisés, les types et fins, permettent à l'étudiant de développer et s'exercer de manière significative pour trouver les moyens de se penser de la science géographique.
\end{abstract}

Mots-clés: Didactique de la géographie; Enseignement de la géographie; Jeux géographiques.

\title{
Introdução
}

O jogo pode ser empregado no processo de ensino e aprendizagem de Geografia como um instrumento mediador das práticas docentes e como uma forma de contribuir para a construção do conhecimento pelo aluno, ajudando-o a desenvolver habilidades geográficas. Entretanto, para que o jogo possa de fato ser um recurso que mobilize desejos no aluno para a apropriação do conhecimento, é importante que o docente articule diferentes saberes e estabeleça claramente os objetivos a serem alcançados.

Cabe então ao professor selecionar as temáticas que almeja trabalhar por meio dos jogos e, visando didatizar os conteúdos geográficos, promover a aprendizagem dos alunos. Para alcançar essa didatização, é preciso que o professor de Geografia articule conhecimentos disciplinares-epistemológicos aos das ciências da educação, ou seja, que combine habilmente conhecimentos da ciência geográfica aos conhecimentos didáticopedagógicos.

Nessa perspectiva, é necessário compreender as potencialidades da utilização de jogos como material lúdico e promotor do processo de ensino e aprendizagem 
considerando a percepção dos próprios professores de Geografia. Assim, este artigo ${ }^{1}$ tem o objetivo de discutir, no contexto das didáticas específicas, a utilização de jogos como recurso didático por professores de Geografia no processo de ensino-aprendizagem. Destarte, são apresentados os procedimentos metodológicos que guiam a pesquisa, bem como os aportes teóricos que a embasam para posteriormente discutirem-se os resultados.

\section{Caminhos da pesquisa: procedimentos metodológicos}

A opção metodológica adotada para a realização desta pesquisa centrou-se em uma abordagem qualitativa do objeto de estudo, sem desconsiderar os dados quantitativos. Para tanto, no início do trabalho, buscaram-se aportes teóricos que subsidiassem as discussões. E a obtenção de dados na pesquisa de campo foi realizada através de dois instrumentos distintos, mas combinados ${ }^{2}:$ questionário e entrevista.

O primeiro instrumento de coleta de dados foi o questionário, com questões objetivas e discursivas elaboradas com o intuito de construir um diagnóstico relativo à temática pesquisada. As questões foram pautadas na procura de informações para compor um panorama geral sobre a formação inicial, a atuação profissional e o uso de jogos em sala de aula pelos docentes participantes. O questionário foi enviado para todos os professores de Geografia vinculados ao Núcleo Regional de Educação de Maringá (NRE/Maringá), Paraná, totalizando 171 docentes, no momento da pesquisa, via e-mail, por meio do formulário do Google Drive, e o retorno com as respostas foi de 55 professores.

O segundo instrumento, um desdobramento do primeiro, consistiu na realização de entrevistas semiestruturadas (GIL 2008; GASKELL, 2002) com quatro docentes selecionados pela análise do questionário visando ao aprofundamento da compreensão dos dados e das informações coletadas. Na realização das entrevistas, foi elaborado um tópico guia que, conforme Gaskell (2002, p.66), “[...] não é uma série extensa de perguntas específicas, mas ao contrário, um conjunto de títulos de parágrafos" e objetiva permitir ao docente entrevistado falar abertamente sobre suas experiências e teorias. Ressalta-se que o tópico guia, como defende Gaskell (2002), permite uma flexibilização e possíveis modificações no roteiro durante as entrevistas, desde que plenamente documentadas, assim como as razões que levaram às mudanças. As entrevistas foram gravadas, as respostas dos entrevistados transcritas com fidelidade e posteriormente analisadas.

$\mathrm{Na}$ análise das falas dos entrevistados foi empregado o método de análise de conteúdo, baseado em Bardin (1977) e Moraes (1999). Essa abordagem metodológica

\footnotetext{
${ }^{1}$ Com base em pesquisa de mestrado intitulada "A utilização de jogos por professores de Geografia na Educação Básica", sob orientação do Prof. Dr. Claudivan Sanches Lopes do Programa de Pós-Graduação em Geografia da Universidade Estadual de Maringá.

${ }^{2}$ Destaca-se que esse processo foi submetido e aprovado por Comitê de Ética em Pesquisa (Copep) da UEM, número do Parecer 2.093.453.
} 
pode ser utilizada para descrever e interpretar diferentes tipos de documentos e textos. Segundo Bardin (1977, p. 42), a análise de conteúdo é:

Um conjunto de técnicas de análise das comunicações visando obter, por procedimentos, sistemáticos e objetivos de descrição do conteúdo das mensagens, indicadores (quantitativos ou não) que permitam a inferência de conhecimentos relativos às condições de produção/recepção (variáveis inferidas) destas mensagens.

Essa análise ajuda a compreender as mensagens contidas no documento e a decifrar seus significados em um nível além de uma leitura comum. Porém, como advoga Moraes (1999, p. 11), "De certo modo a análise de conteúdo, é uma interpretação pessoal por parte do pesquisador com relação à percepção que tem dos dados. Não é possível uma leitura neutra. Toda leitura se constitui numa interpretação".

Os resultados das análises das respostas dos questionários foram discutidos levando-se em conta três tópicos analíticos: 1) Criação e utilização dos jogos; 2) Objetivos da utilização dos jogos em sala de aula; e 3) Tipos de jogos utilizados. As entrevistas, realizadas com as professoras Marta, Ana, Elisa e Alice ${ }^{3}$, buscaram aprofundar os resultados e as análises. Assim, os dados coletados, à luz dos objetivos da pesquisa e da metodologia da análise de conteúdo (BARDIN, 1977; MORAES, 1999), foram também agrupados em categorias analíticas. Neste trabalho, discutem-se as seguintes categorias: 1) Motivação para utilizar os jogos em sala de aula; 2) A finalidade dos jogos em sala de aula; 3) As tipologias dos jogos empregados nas aulas de Geografia; 4) Os jogos e o desenvolvimento do raciocínio geográfico no aluno; e 5) As dificuldades enfrentadas para empregar jogos no processo de ensino e aprendizagem de Geografia.

Neste artigo, apresentam-se as análises das categorias de forma integrada, articulando as respostas dos questionários às respostas das entrevistas, com a finalidade de atingir uma compreensão mais ampla das discussões realizadas na pesquisa.

\section{Didática da Geografia}

A Geografia fornece concepções teóricas para a compreensão das relações sociais que, contínua e ininterruptamente, modificam o espaço geográfico, bem como sua organização. Na escola, os conteúdos trabalhados na disciplina de Geografia contribuem não apenas para que o aluno entenda a lógica da organização do espaço, mas que visualize seu papel nas decisões que o modelam e o transformam. Essa disciplina almeja, portanto, oferecer instrumentos teóricos e práticos de modo que os alunos possam pensar e agir sobre/no espaço. Corroborando Sacramento (2010, p. 5), "O papel atual da Geografia Escolar é fazer com que o aluno compreenda os fenômenos geográficos espacializados em seu cotidiano, permitindo-lhe localizar-se e perceber tais transformações".

\footnotetext{
${ }^{3}$ Para preservar a identidade das professoras, os nomes adotados são fictícios.
} 
O professor de Geografia exerce o papel de mediador do conhecimento selecionado pelo currículo escolar, fornecendo aos alunos, por meio de suas práticas, conceitos que lhes permitem interpretar o mundo em uma perspectiva geográfica e desenvolver um pensamento crítico. $\mathrm{O}$ docente contribui, pelo uso combinado dos conteúdos e dos procedimentos investigativos próprios dessa disciplina, para que o aluno desenvolva um tipo especial de raciocínio: o geográfico. Nessa direção, de acordo com Sacramento (2010), ensinar Geografia é permitir que o aluno compreenda as consequências dos fenômenos geográficos em sua própria vida e na sociedade como um todo.

Nessa perspectiva, Castellar e Vilhena (2011, p. 19) assinalam que "Ensinar geografia significa possibilitar ao aluno raciocinar geograficamente o espaço terrestre em diferentes escalas, numa dimensão cultural, econômica, ambiental e social". Nesse âmbito, indaga-se: Como efetivar essa ambiciosa ação? Como enfrentar o desafio de fazer da Geografia uma disciplina interessante para o aluno e superar definitivamente ideia de um amontoado de conteúdos sem sentido pra a vida? Como construir uma didática para a Geografia?

É importante, segundo Callai (1999), que os conteúdos tenham relação com a vida e a realidade dos alunos, e que estes possam compreender o espaço construído e transformado pela sociedade como resultado da ação dos seres humanos. Nesse ponto, a educação geográfica se mostra importante e significativa para o aluno, pois

[...] através da educação geográfica, se busca construir uma forma geográfica de pensar, que seja mais ampla, mais complexa, e que contribua para a formação dos sujeitos, para que estes realizem aprendizagens significativas e para que a geografia seja mais do que ilustração (CALLAI, 2011, p. 129).

O professor, então, instrumentaliza teoricamente os alunos para ler o mundo, ou seja, ensina conceitos que permitem aos discentes manipular e analisar informações que lhes possibilitarão construir uma consciência cidadã sobre o espaço em que vivem. É possível, por conseguinte, que os alunos, mediados pela prática docente, desenvolvam um olhar geográfico acerca do mundo e por meio da educação geográfica percebam as relações existentes no espaço em que vivem, pois como argumenta Callai (1999, p. 58), a Geografia ensinada deve permitir ao aluno se perceber "[...] como participante do espaço que estuda, onde os fenômenos que ali ocorrem são resultados da vida e do trabalho dos homens e estão inseridos num processo de desenvolvimento".

Nessa direção, para alcançar esses objetivos é preciso que o professor de Geografia tenha o domínio das bases da ciência e dos conhecimentos didáticopedagógicos, articulando os saberes a ensinar aos modos de ensinar. Isso contribui para que o docente construa uma didática específica da Geografia que se fundamenta na junção entre o pedagógico e o epistemológico, construindo dessa forma meios didáticos de alcançar um ensino significativo. Assim, sem desconsiderar as condições em que, de modo geral, a profissão docente é exercida e os diversos elementos que influência a 
aprendizagem, o docente pode, através da didática dessa ciência, proporcionar aos alunos elementos que lhes possibilitem compreender as transformações e construções do espaço geográfico, fazendo leituras, comparações, relações e análises das informações.

O docente, ao longo de sua carreira profissional, mobiliza diferentes saberes, adquiridos durante seu processo formativo e ao longo de sua carreira profissional, cujo objetivo mais imediato é a edificação de suas práticas e consequente didatização dos conteúdos trabalhados em sala de aula. São diversas as pesquisas, como as efetuadas por Tardif (2002), Gauthier et al. (1998) e Shulman (2014), que buscam conhecer e compreender o processo de aquisição e desenvolvimento desses saberes docentes. Destaca-se, sem o objetivo de discutir as especificidades destas, que esses estudos subsidiaram e têm impulsionado o aprofundamento dos trabalhos relativos às didáticas específicas, com ênfase ao conhecimento pedagógico do conteúdo identificado por Shulman (2014), pois se constitui na inter-relação entre matéria e pedagogia.

Libâneo (2016, p. 354) em seus estudos assevera que:

[...] tem se fortalecido o entendimento de que a didática não pode formular seu objeto de estudo sem a consideração dos conteúdos e métodos das ciências a serem ensinadas, assim como as didáticas específicas não podem cumprir sua tarefa na formação de professores sem os princípios de aprendizagem e ensino comuns a todas as disciplinas.

É necessária, assim, uma junção entre o pedagógico e o epistemológico, pois tanto os conhecimentos mais gerais da didática (que transcendem o campo específico de cada disciplina) são importantes para o ensino quanto as peculiaridades de cada ciência. Cabe ao docente articular os conhecimentos disciplinares, ou seja, os conhecimentos que provêm dos diferentes campos da ciência, como os da Geografia, da História, da Matemática ou outra, com os conhecimentos didático-pedagógicos que são os conhecimentos da didática e demais disciplinas ligadas ao ensino.

Em sua prática, o professor deve selecionar a melhor forma de se trabalhar um conteúdo, pois conforme Libâneo (2016, p. 355), “[...] o conhecimento do conteúdo e o conhecimento didático do conteúdo estão mutuamente relacionados, sendo este último vinculado diretamente aos conteúdos e procedimentos lógicos e investigativos da ciência que está sendo ensinada".

Ao articular o pedagógico ao epistemológico, surge um modo de ensino próprio de cada ciência, sem desconsiderar os conhecimentos didáticos comuns a todas as disciplinas vinculadas ao ensino, nem os conteúdos próprios de cada ciência. Isso permite ao docente trabalhar os conteúdos em sala de aula de maneira que os alunos avancem no conhecimento do que é ensinado.

Destarte, é necessário que o docente articule diferentes saberes, considerando fundamentalmente aqueles próprios da Geografia, pedagógicos e também do contexto de seus alunos para alcançar um ensino de Geografia efetivo. Lopes (2016) salienta que a 
construção e o desenvolvimento da Didática da Geografia dependem, em uma complexa atividade, da articulação entre os conhecimentos da ciência geográfica e os conhecimentos pedagógicos.

O desenvolvimento da didática própria da Geografia possibilita ao docente, entre outros, identificar a forma mais adequada e que mais pode contribuir para o ensino de determinado conteúdo, como, por exemplo, a escolha da utilização do jogo em sala de aula. O jogo torna-se um momento especial para se estudar o processo de didatização dos conteúdos, de examinar a inseparabilidade de conteúdos específicos e a pedagogia.

\title{
Os jogos no ensino de Geografia
}

A disciplina de Geografia, por meio de seus conceitos, permite realizar uma leitura do espaço vivido. E é o docente, em suas práticas pedagógicas, que torna o ensino de Geografia significativo para o aluno, permitindo que este desenvolva habilidades de observar, comparar, analisar e interpretar a realidade e que desenvolva um olhar geográfico para ler o mundo. Nessa perspectiva Callai (2011, p. 129) pontua que

\begin{abstract}
A geografia escolar se constitui como um componente do currículo, e, seu ensino, se caracteriza pela possibilidade de que os estudantes percebam a singularidade de suas vidas e, reconheçam a sua identidade e o seu pertencimento em um mundo que a homogeneidade apresentada pelos processos de globalização trata de tornar tudo igual. É, portanto uma matéria curricular que encaminha a compreender o mundo e, às pessoas a se entenderem como sujeitos neste mundo, reconhecendo a espacialidade dos fenômenos sociais.
\end{abstract}

O professor dessa disciplina, para alcançar seus objetivos, desenvolve modos próprios de ensinar os diferentes conteúdos geográficos, ou seja, uma didática própria da Geografia fazendo uso de múltiplos instrumentos, dentre os quais os recursos didáticos como o jogo, o qual possui uma função pedagógica que "[...] pode ser usada para romper com práticas tradicionais no processo de ensino e de aprendizagem, uma vez que o professor consiga traçar etapas na construção e na produção do jogo" (CASTELLAR e VILHENA, 2011, p. 46).

Nesse sentido, os jogos podem ser empregados no ensino de Geografia como um caminho de didatização dos conteúdos geográficos, pois são capazes de contribuir para a articulação da teoria e da prática no desenvolvimento do raciocínio geográfico no aluno. Em consonância com Girotto (2015, p. 72), o raciocínio geográfico é “[...] a capacidade de estabelecer relações espaço-temporais entre fenômenos e processos, em diferentes escalas geográficas". E como pontuam Castellar e Vilhena (2011, p. 44), “[...] os jogos auxiliam a aprender a pensar sobre o espaço em que se vive", e contribuem para a construção de habilidades geográficas.

Oliveira e Lopes (2016, p. 174) asseveram que "Ao jogar um jogo em sala de aula os alunos devem exercitar e interiorizar modos de pensar, de raciocinar e de 
investigar, próprios da ciência ensinada". Isto é, as situações problema apresentadas pelo jogo, os objetivos a serem alcançados em seu desenrolar precisam exigir o uso dos conhecimentos e das habilidades vinculadas à ciência geográfica. Além disso, esses materiais devem viabilizar a interação entre os alunos e o professor, oportunizando uma cooperação entre os discentes que jogam, porque um aluno pode ajudar e incentivar o colega a expandir o conhecimento sobre aquele conteúdo. Castellar e Vilhena (2011, p.45) declaram que

[...] os jogos e as brincadeiras são entendidos como uma situação em que se tem de tomar decisões e cooperar com os outros jogadores. Nesse momento, espera-se desenvolver situações de aprendizagem voltadas para as atitudes, focadas na formação cidadã e no respeito ao próximo.

Esse recurso didático pode revelar-se interessante para o processo de ensino e aprendizagem de Geografia e para a formação de sujeitos críticos, conscientes e questionadores. É capaz de possibilitar que os alunos se arrisquem a propor soluções para problemas encontrados no jogo e que refletem o seu cotidiano, visualizando seu papel na sociedade e pensando no espaço em que vivem de maneira local e global. Assim,

\begin{abstract}
A realização do jogo na disciplina possibilita a construção de habilidade que auxiliarão na produção lógica do conhecimento, permitindo a associação com outros conteúdos e dinamizando a aula, uma vez que os alunos gostam de jogar, de realizar uma atividade diferente (CASTELLAR; VILHENA, 2011, p. 48).
\end{abstract}

Observa-se, portanto, que os jogos permitem a integração e o envolvimento dos alunos nas atividades de modo que aprendem e avançam no conhecimento de maneira prazerosa, alegre e divertida. Com base em conteúdos científicos, esses recursos podem tornar o ensino de Geografia mais significativo para os discentes, que aprendem de maneira lúdica.

Convém realçar que não é o uso do jogo pelo jogo que contribui para o ensino significativo nesse campo do currículo escolar, mas sim o conteúdo e a forma geográfica do material, que possibilitam aos alunos progredir na construção do conhecimento geográfico. Desse modo, para além das possibilidades de socialização como, por exemplo, o desenvolvimento de hábitos coletivos de trabalho (superação do egocentrismo) e valores relacionados à cooperação, o jogo propriamente geográfico deve mobilizar no aluno um raciocínio geográfico.

Com o apoio dos referenciais teóricos expostos, apresentam-se a seguir alguns resultados obtidos na pesquisa com a análise dos dados coletados por meio de questionários e entrevistas. 


\section{O uso de jogos: das motivações às dificuldades}

Os dados coletados apontaram que os jogos vêm sendo utilizados por uma parcela significativa de professores, pois como se pode observar na Figura 1, dos 55 participantes da pesquisa, 41 (74,5\% do total) revelaram fazer uso desse recurso nas aulas e apenas 14 (25,4\% do total) relataram não empregar esses materiais. Isso se torna positivo à medida que, como verificado em Grando (2000), Castellar e Vilhena (2011) e Oliveira e Lopes (2016), esse instrumento é capaz de auxiliar o aluno na compreensão de conceitos abstratos de maneira concreta, prosseguindo na construção de habilidades geográficas como a observação, orientação e análise, além de desenvolver um olhar geográfico crítico sobre a sociedade em que vive.

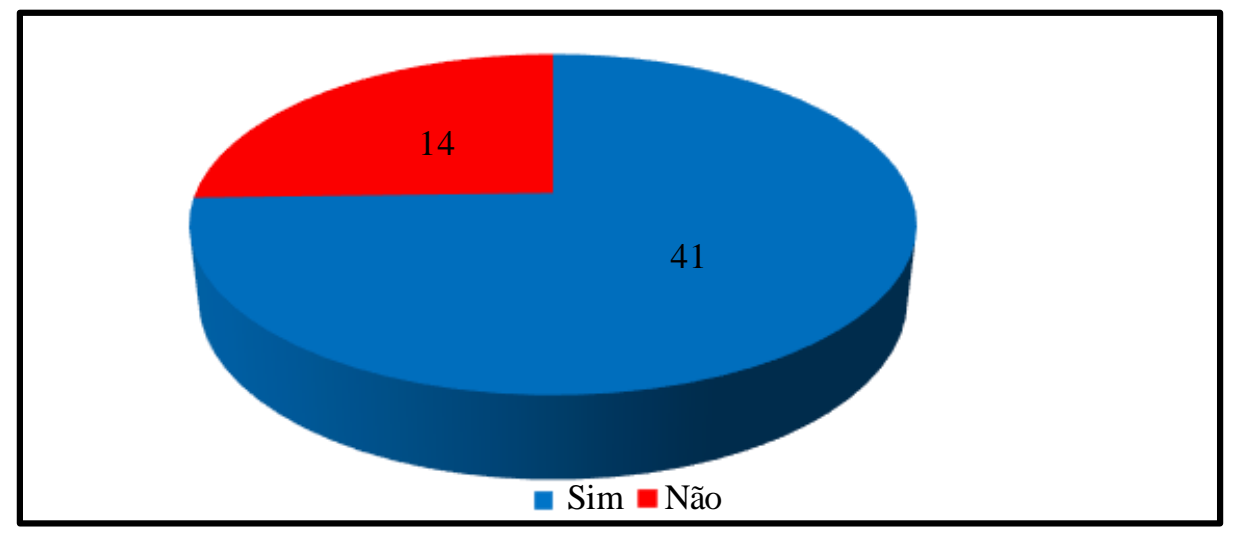

Figura 1: Utilização dos jogos em sala de aula

Fonte: Oliveira (2018).

Ao se considerar o número de professores que utilizam os jogos em suas práticas pedagógicas, é perceptível que esses materiais podem ser empregados em diversos momentos ao se trabalhar dado conteúdo (OLIVEIRA; LOPES, 2016). É possível abordar diferentes temas com esses recursos, ainda que não sejam, indistintamente, uma solução para ensinar todos os conceitos e resolver todos os problemas do professor: não é mágico.

Grando (2000) afirma que o planejamento e o apoio, em uma reflexão teóricometodológica, são essenciais para a inserção dos jogos no processo de ensino e aprendizagem, pois definirão se o jogo é pertinente ou não para a sua proposta de ensino. Isso leva a questionamentos sobre como, de modo geral, os professores utilizam os jogos em sala de aula: O que os motiva a empregar esses materiais? Com quais finalidades? Que tipos de jogos são usados? Quais são as dificuldades enfrentadas?

Em consonância com as falas das professoras entrevistadas, bem como, dos participantes dos questionários e considerando as motivações dos docentes para empregar os jogos em sala de aula, nota-se que o lúdico está presente em suas práticas 
pedagógicas por múltiplos motivos, sendo eles: aspiração pessoal, busca em diversificar e inovar as suas práticas pedagógicas, procurando superar as práticas tidas como tradicionais. É o caso da professora Marta, que revela:

$\mathrm{Na}$ realidade o aluno ele pede uma aula diferenciada, porque nem todos os alunos conseguem atingir o conhecimento através do quadro, [...]. E eu acho que através dos jogos, através das atividades lúdicas, o aluno ele se solta e ele consegue trabalhar de uma outra forma [...] (PROFESSORA MARTA).

Outra motivação é o emprego dos jogos como forma de aproximação, interação com os alunos e com a realidade que os envolve, como se pode observar na fala da professora Ana, que diz: "Na verdade, na sala de aula você nota que o conteúdo, o livro em si, ele é pouco, você precisa tentar um mecanismo pra se aproximar das crianças, pra se aproximar da realidade [dos alunos]". Corroborando a motivação da professora, Castellar e Vilhena (2011), Grando (2000) e Rau (2012) sustentam que os jogos podem viabilizar maior interação dos alunos com o docente e propiciar uma cooperação entre os próprios discentes, os quais contribuem, consequentemente, para que o colega avance no jogo e na aprendizagem dos conteúdos.

Além das motivações, os dados da pesquisa revelaram as múltiplas finalidades para as quais os jogos são empregados nas aulas de Geografia. Segundo os participantes, o emprego desse instrumento depende do conteúdo a ser ensinado e, evidentemente, do planejamento realizado pelo docente a partir de seus saberes. Para eles, os principais usos desses recursos atende finalidades como: fechar um conteúdo (ou seja, ao finalizar uma temática se implementa o jogo), retomar um conceito, como a avaliação, promover a interação dos alunos, a construção de determinados conceitos geográficos, desenvolver habilidades ligadas às noções cartográficas, superar dificuldades de aprendizagem em alguns conteúdos, tidos como mais abstratos e difíceis, fixar conteúdos e construir conceitos.

Verificou-se, assim, que o uso dos jogos para finalizar um conteúdo é recorrente entre os pesquisados, fato que ficou evidente nas falas das professoras Marta, Ana e Elisa, as quais afirmaram empregar os jogos para fechar uma temática, avaliando a compreensão dos alunos acerca do conteúdo trabalhado. Nessa direção Elisa relata: "eu gosto muito quando estou terminando o conteúdo fechar com o jogo, pra que ele [o aluno] memorize melhor; é através dos jogos que eu acho que ele internaliza melhor o conteúdo".

Outra finalidade também citada, por uma parcela significativa de participantes, foi o emprego desses materiais com a finalidade de auxiliar o desenvolvimento de habilidades, ligadas às noções cartográficas, e superar dificuldades de aprendizagem em conteúdos abstratos. Corroborando a ideia, a professora Alice assinala trabalhar muito "[...] com as questões cartográficas, por exemplo, localização espacial, conceitos da Geografia (grifo nosso)". E complementa: "Olha, eu trabalho com jogos principalmente quando tem conteúdos que eles são muito abstratos pros alunos e aí tem que tornar esse 
conteúdo mais prático, é aí que eu entro com os jogos". Esse ponto é importante, visto que o jogo pode permitir a visualização e a apropriação de conteúdos abstratos (CASTELLAR; VILHENA, 2011), possibilitando a construção de conceitos, habilidades e a expansão do conhecimento.

A finalidade mais citada pelos participantes é o emprego dos jogos visando à fixação dos conteúdos e, em menor número, com finalidade mais específica como, por exemplo, a construção de determinados conceitos e o desenvolvimento de habilidades geográficas. Entende-se que estas últimas finalidades requerem um processo de elaboração mais complexo e exigente, porque é necessário alcançar, em conjunto com o aluno, um avanço no conhecimento e superar o aspecto mnemônico do ensino. Trata-se, dessa maneira, de uma lacuna a ser preenchida, a criação e o desenvolvimento de jogos geográficos atrelando forma e conteúdo geográfico.

Esses dados estão conectados, direta e indiretamente, aos tipos de jogos empregados pelos professores em sala de aula, pois a pesquisa revelou, como se pode verificar na Figura 2, que os tipos de jogos mais utilizados são os materiais adaptados e, em sua maior parcela, os jogos de pergunta e resposta e de montagem ${ }^{4}$. São jogos que possibilitam maiores alterações e consequentemente, com mais facilidade, atingir os objetivos e finalidades propostas com o uso do material.

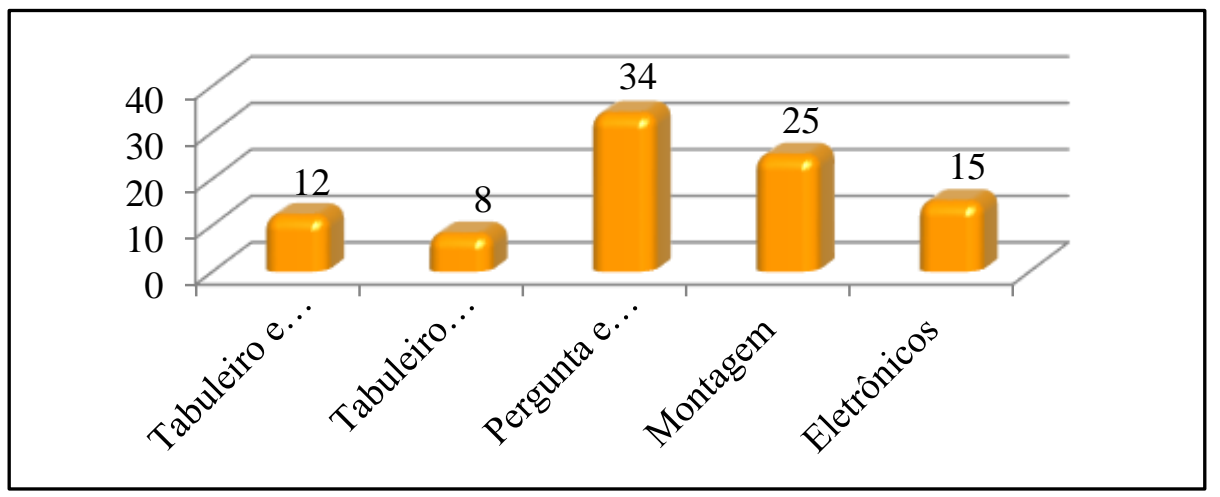

Figura 2: Tipologia dos jogos usados em sala de aula Fonte: Oliveira (2018).

Esses tipos de jogos, apresentados na Figura 2, são os mais visados por suas características e por permitirem maiores adaptações ao conteúdo, bem como, ao nível de conhecimento e comportamento da turma em que são empregados. Dessa maneira, os professores se apropriam de jogos, já conhecidos e simples, e inserem o conteúdo a ser

\footnotetext{
4 Oliveira (2018, p. 62) acentua que os jogos de pergunta e resposta são os jogos de questionários em que os participantes são submetidos a diversas perguntas, que podem ser temáticas ou multitemáticas, tentando acertar o maior número de questões para vencer. E jogos de montagem são jogos nos quais o jogador precisa montar diversas peças para completar o jogo, como o quebra-cabeça e o dominó.
} 
trabalhado na aula de acordo com seus objetivos. Confirmando isso a professora Elisa revelou empregar, em suas aulas, caça-palavras, cruzadinha, dominó, jogos de tabuleiro, batalha naval e ainda jogos eletrônicos, reverberando a tipologia sinalizada nos questionários, visando a atender as necessidades de cada turma. No entanto, ressalta-se que nem todos os entrevistados partem do formato do jogo: uma parcela revelou seguir do conteúdo para então selecionar o tipo, e nenhum professor afirmou atrelar conteúdo e forma de maneira conjunta.

Além dessas possíveis adaptações e modificações através da tipologia dos materiais, os docentes indicaram ainda possibilitar aos discentes elaborar alguns dos jogos utilizados, permitindo que participem ativamente da construção do seu próprio conhecimento, tanto ao elaborar os materiais quanto ao jogá-los. Nessa direção, a professora Alice relatou que "Têm jogos que dá pra montar com os próprios alunos, mas têm jogos que aí eu faço uma adaptação". Corroborando essa ideia, Grando (2000) destaca a possibilidade de interação dos alunos com os jogos, como assinalado, e a oportunidade da participação ativa do discente na construção de seu próprio conhecimento. A professora Alice ainda complementou que "Eu vou modificando, de um ano pra outro eu vou modificando [os jogos]". Dessa forma, os materiais utilizados por ela são sempre renovados, atendendo à demanda dos alunos e às especificidades de cada turma. Infere-se que os jogos, então, devem ser utilizados de modo flexível, mediados pelo discernimento pedagógico do professor.

Ao interligar as tipologias, já discutidas, com as finalidades de fixação de conteúdo e construção de conceito, elaborou-se uma classificação, exposta no Quadro 1. Essa categorização baseia-se na forma e no conteúdo do jogo e objetiva verificar a geograficidade dos materiais utilizados, e de maneira abrangente, as metas que o docente pretende atingir ao empregar o jogo em sala de aula.

Quadro 1: Classificação dos jogos utilizados pelos participantes

\begin{tabular}{|l|c|c|}
\cline { 2 - 3 } \multicolumn{1}{c|}{} & \multicolumn{2}{c|}{ Conteúdo } \\
\hline \multicolumn{1}{c|}{ Forma } & Fixação de conteúdo & Construção de conceitos \\
\hline $\begin{array}{l}\text { Jogos de tabuleiro e de } \\
\text { estratégia }\end{array}$ & $3^{5}$ & 9 \\
\hline Jogos de tabuleiro com trilha & 4 & 4 \\
\hline Jogos de pergunta e resposta & 22 & 12 \\
\hline Jogos de montagem & 17 & 8 \\
\hline Jogos eletrônicos & 9 & 6 \\
\hline
\end{tabular}

Fonte: Oliveira (2018).

Ao observar a tipologia dos jogos de acordo com a forma e o conteúdo, verifica-se, como apontado, que os jogos de pergunta e resposta, aplicados em busca da

\footnotetext{
${ }^{5}$ Os números correspondem às respostas dos professores, de acordo com o que assinalaram na questão sobre a tipologia e na questão a respeito da finalidade de fixação de conteúdo ou construção de conceito; os participantes tinham a possibilidade de assinalar mais de um tipo de jogo.
} 
fixação de conteúdo, são os mais utilizados, seguidos pelos jogos de montagem, com a mesma finalidade. Isso possibilita entender o modo como os professores percebem os jogos no ensino de Geografia e os utilizam em suas práticas.

O emprego dos materiais elencados como mais empregados, associados à fixação do conteúdo, busca, dentre outras funções, contribuir para a gestão da classe, para a organização e administração do comportamento da turma. Uma utilização que, embora atribua menor preocupação aos conteúdos geográficos e não deva ser o principal objetivo do uso do jogo, torna o jogo um instrumento que auxilia o docente. Estas tipologias são utilizadas, também, para realizar revisões de conteúdos e aproximação com os discentes.

Essa classificação indica, ainda, as condições concretas nas quais esses docentes trabalham, sabidamente, inibidoras da criatividade docente. Condições como a falta de tempo e de recursos materiais e as condições adequadas para sua produção de materiais, além das precárias condições de infraestrutura que caracterizam boa parte das escolas brasileiras, dificultam o acesso e elaboração de jogos mais complexos.

Isto posto, buscou-se compreender, na perspectiva dos participantes, o que é um jogo geográfico e o que o torna geográfico. As professoras entrevistadas, unanimemente, entendem que para ser geográfico um jogo deve abordar conteúdos e conceitos básicos dessa disciplina, aproximando-se do que foi manifestado nos questionários, nos quais a maior parcela dos participantes assinalou que as temáticas abordadas no jogo são o que o torna geográfico.

Outro entendimento identificado nas respostas dos participantes é que, para ser geográfico, o jogo necessita desenvolver habilidades nos alunos e contribuir para uma educação geográfica significativa. E, em menor número, identificou-se que para alguns docentes o que torna um jogo geográfico é, além do conteúdo, a forma desse material e o que nele está expresso.

Com o apoio da bibliografia consultada (CASTELLAR; VILHENA, 2011; OLIVEIRA; LOPES, 2016), aponta-se que a caracterização de um jogo propriamente geográfico, mais do que apenas contemplar conteúdos ou temáticas desse campo disciplinar, define-se pela inter-relação que deve haver entre a forma e o conteúdo do material. O jogo deve mobilizar ainda, por meio dessa articulação, os motivos (desejos e interesses) pelo conteúdo de ensino e não simplesmente o interesse do aluno mais imediato de se divertir ou se descontrair, possibilitando a este desenvolver o raciocínio geográfico, objetivo fundamental da educação geográfica. Desse modo, esses materiais se tornam um instrumento pedagógico para o docente e um caminho de didatização dos conteúdos dessa disciplina.

O jogo, para ser efetivamente geográfico - ou geograficamente pedagógico ou pedagogicamente geográfico - deve mobilizar nos alunos os motivos para aprender e avançar no conhecimento. Se o envolvimento destes com o jogo ocorrer apenas no campo de suas emoções, isso pode lhes proporcionar prazer, sem, contudo, haver apropriação dos conteúdos. Nesse caso, ainda que não desapareça sua função 
socializadora, o jogo se afasta de suas possibilidades cognoscitivas e esvazia-se de suas ambições propriamente geográficas, pois não deve ficar restrito somente ao campo do divertir-se e descontrair-se. Todavia se, além do campo das emoções, o envolvimento se der pelo despertar da importância individual e coletiva dos conteúdos geográficos que o estrutura, o jogo cumpre plenamente seus objetivos educativos.

É necessário realçar que são as habilidades mobilizadas no aluno, como localização, orientação, observação, descrição, interpretação, análise, dentre outras, que constituem sua capacidade de compreender, espacial e temporalmente, o espaço e os fenômenos que nele se constituem, ou seja, raciocinar geograficamente para perceber e compreender o espaço em que vivem. Para que isso seja possível, o docente, mediador do conhecimento, através de seu arcabouço de saberes, deve construir práticas pedagógicas que permitam aos alunos desenvolver esse raciocínio geográfico.

Diante dessas assertivas, que descrevem positivamente o jogo como um instrumento que contribui para o ensino de Geografia, é necessário pontuar que os docentes participantes da pesquisa demonstraram empregar os jogos reconhecendo sua importância no ensino. Contudo, apontaram que são grandes as dificuldades encontradas nesse processo, tanto por questões ligadas ao comportamento dos alunos, pela falta de recursos materiais, quanto pela infraestrutura das escolas.

Alguns autores consultados para a elaboração deste trabalho (GRANDO, 2000; KAMII; DEVRIES, 1991) salientam as dificuldades de implementação dos jogos quando falta um planejamento adequado. Dentre os pontos tidos como negativos do uso desses recursos para estes autores estão o perigo de dar ao jogo um caráter puramente aleatório; o tempo gasto com as atividades; a competição (refutada como ponto negativo por alguns); a dificuldade de acesso e a disponibilidade de material teórico e prático.

Os participantes da pesquisa revelaram que as principais dificuldades enfrentadas ao se utilizar os jogos em sala de aula são a falta de materiais, a indisciplina dos alunos e a falta de infraestrutura das escolas. De modo geral, trata-se de situações estruturais do sistema de ensino, que condicionam e limitam a prática dos professores, confirmando, em parte, o contido na literatura consultada.

A fala da professora Marta reafirma essas ponderações: a partir de suas práticas, considera que duas situações restritivas importantes são "o tempo dentro escola pública" e "a falta de material, porque às vezes a professora tem que elaborar [o jogo] na sua casa, com seu próprio material”. São as dificuldades por ela enfrentadas ao utilizar os jogos em sala de aula, enfatizando os problemas estruturais.

A professora Alice corrobora: "É o tempo pra confecção desse material o maior inimigo, é o tempo, o material não, material a gente disponibiliza, a escola também ajuda. Mas é o tempo pra confecção desse material [a dificuldade]”. A docente evidencia, portanto, a partir de suas práticas e experiências ao longo da profissão, que não identifica pontos negativos do jogo propriamente dito. Porém, aproximando-se da opinião emitida pelos demais pesquisados, ressalta que o tempo gasto para elaborar o 
material - ou seja, mais uma vez questões estruturais - é a maior dificuldade a ser enfrentada para utilizar esses recursos.

As questões estruturais do sistema de ensino - o fator tempo, a falta de recursos materiais e de condições adequadas para sua produção - constituem, na percepção das entrevistadas e nos resultados obtidos mediante a aplicação dos questionários e a própria literatura na área, os principais empecilhos ou pontos negativos para o uso dos jogos nas salas de aula de Geografia. É evidente que o jogo, especificamente, pode apresentar fatores negativos como a competição, a bagunça em excesso, especialmente quando falta um planejamento adequado. No entanto, os problemas de infraestrutura das escolas se sobressaem largamente a esses aspectos do material.

\section{Conclusão}

Com base na bibliografia estudada e nas análises dos dados coletados na pesquisa de campo, é possível inferir que o emprego dos jogos no processo de ensino e aprendizagem de Geografia, no âmbito do universo pesquisado, é recorrente e apresenta resultados satisfatórios em uma parcela significativa desse uso. Os materiais são considerados, pelos entrevistados, como capazes de auxiliar o docente no processo de ensino e permitir que o aluno transponha as dificuldades de aprendizagem em alguns conteúdos, entendidos como os mais difíceis. Podem também, por sua natureza lúdica, despertar o interesse do discente pelo conteúdo e diversificar as formas de ter contato com os conceitos da disciplina. São capazes, ainda, de contribuir de maneira significativa para a interação dos alunos entre si, com o conteúdo e com os professores.

Evidenciou-se que é necessário que o docente elabore ou selecione materiais que além do conteúdo também apresentem um formato geográfico, que revelará, dessa maneira, por meio da inter-relação entre a sua forma e seu conteúdo a efetiva geograficidade do jogo. Expondo a temática a ser estudada de maneira articulada, o discente então avança no conhecimento, pois assim, os problemas ou desafios colocados pelas situações do jogo exigem a utilização dos conceitos geográficos e habilidades a eles relacionadas.

A pesquisa mostrou, além de diversos fatores positivos na implementação dos jogos em sala de aula, alguns pontos negativos e as dificuldades no emprego desses materiais. De modo geral, as respostas dos entrevistados evidenciaram dificuldades com relação ao comportamento dos alunos, à indisciplina, à criação e acesso aos materiais, ou seja, falta de materiais prontos, carência de recursos para elaboração e confecção dos jogos, a precária infraestrutura pedagógica das instituições de ensino. Também relataram o fator tempo como grande dificuldade, seja para elaborar o material ou para o uso em sala de aula.

Entretanto, ainda que diante de dificuldades, os jogos, na percepção dos professores pesquisados, criam um ambiente que possibilita aos alunos acessar conceitos que lhes permitem desenvolver habilidades e raciocinar geograficamente para ler o espaço geográfico. 
Frisa-se que, para apoiar essas práticas, se faz necessária uma reflexão sobre a didática da Geografia e a teorização relativa ao uso dos jogos, para que os professores, com esse embasamento, possam construir e escolher materiais, isto é, jogos geográficos que atinjam os objetivos desejados e atendam às demandas e necessidades dos alunos. Entende-se, destarte, que a ampliação das possibilidades do uso eficaz do jogo no ensino de Geografia depende, paralelamente, da ação inventiva dos professores em sala de aula - não raramente heroico em função das condições de trabalho oferecidas de modo geral pela escola pública no Brasil - de um processo mais sistemático de pesquisa e reflexão teórica que possa subsidiar suas práticas.

\section{Nota:}

O presente trabalho foi realizado com apoio da Coordenação de Aperfeiçoamento de Pessoal de Nível Superior - Brasil (Capes) - Código de Financiamento 001.

\section{Referências}

BARDIN, L. Análise de Conteúdo. Lisboa - Portugal, Edições 70, 1977.

CALLAI, H. C. A GEOGRAFIA ESCOLAR - E OS CONTEÚDOS DA GEOGRAFIA. Revista Anekumene, Vol1, nº 1, 2011. Disponível em <http://www.anekumene.com/index.php/revista/article/view/14/15> Acesso em: 16 de Fevereiro de 2017.

CALLAI, H. C. O ensino de Geografia: recortes espaciais para análise. In.

CASTROGIOVANNI, A. C. et al. (Org.). Geografia em sala de aula: práticas de reflexões. Porto Alegre: Ed. da Universidade/UFRGS/AGB-PA, p.57-66, 1999.

CASTELLAR, S., VILHENA, J. Ensino de Geografia. São Paulo: Cengage Learning, 2011.

GASKELL, G. Entrevistas individuais e grupais. In. BAUER, M. W.; GASKELL, G. Pesquisa qualitativa com texto, imagem e som: um manual prático. 2. Ed. Petrópolis, RJ: Vozes, 2002.

GAUTHIER, C. et al. Por uma teoria da pedagogia: pesquisas contemporâneas sobre o saber docente. Ijuí, RS: Unijuí, 1998.

GIL, A. C. Métodos e técnicas de pesquisa social. 6. ed. São Paulo: Atlas, 2008.

GIROTTO, E.D. Ensino de Geografia e raciocínio geográfico: as contribuições de Pistrak para a superação da dicotomia curricular. Revista Brasileira de Educação em Geografia, Campinas, v. 5, n. 9, p. 71-86, jan./jun., 2015.

GRANDO, R. C. O conhecimento matemático e o uso de jogos na sala de aula. 2000. 224f. Tese (Doutorado em Educação, subárea em Matemática). Universidade Estadual de Campinas, Faculdade de Educação. Campinas, São Paulo, 2000. 
KAMII, C.; DEVRIES, R. Jogos em grupo na educação infantil: implicações da teoria de Piaget. Trad. Marina Célia Dias Carrasqueira. São Paulo: Trajetória Cultural. 1991.

LIBÂNEO, J. C. A teoria do ensino para o desenvolvimento humano e o planejamento de ensino. Educativa, Goiânia, v. 19, n. 2, p. 353-387, 2016. Disponível em <

http://seer.ucg.br/index.php/educativa/article/view/5391/2954> Acesso em: 20 de Fevereiro de 2017.

LOPES, C. S. O trabalho pedagógico do professor de Geografia e seus saberes. In PORTUGAL, J. F (et.al.). Formação e docência em Geografia: narrativas, saberes e práticas. Salvador: EDUFBA, p. 21-40. 2016.

MORAES, R. Análise de conteúdo. Revista Educação. Porto Alegre, ano 22. p. 7-37, 1999.

OLIVEIRA, T. P., LOPES, C. S. “Acertando as Horas”: Jogo Cartográfico como Recurso Didático Geográfico no Ensino de Fusos Horários. Revista Tamoios, Rio de Janeiro, ano 12, n. 2, p. 171-189. 2016.

OLIVEIRA, T. P. A utilização de jogos por professores de Geografia na educação básica. 2018. 151f. Dissertação (Mestrado em Geografia) Programa de Pós-Graduação em Geografia da Universidade Estadual de Maringá. Maringá, 2018.

SACRAMENTO, A. C. R. Didática e Educação Geográfica: algumas notas. UniPluri/Versidad. Facultad de Educación- Universidad de Antioquia. Medellín, Col. Vol.10, N. 3, p. 1-9, 2010. Disponível em

〈https://aprendeenlinea.udea.edu.co/revistas/index.php/unip/article/viewFile/9581/8821 >. Acesso em 02 set. 2017.

SHULMAN, L. S. Conhecimento e ensino: fundamentos para a nova reforma. Tradução de Leda Beck. São Paulo, Cadernoscenpec, v.4, n.2, p.196-229, 2014. Disponível em <http://cadernos.cenpec.org.br/cadernos/index.php/cadernos/article /view/293/297> Acesso em: 02 set. 2016.

TARDIF, M. Saberes docentes e formação profissional. Tradução de Francisco Pereira. Petrópolis, RJ: Vozes, 6. ed. 2002.

Tais Pires de Oliveira

Doutoranda em Geografia pelo programa de Pós-Graduação em Geografia na Universidade Estadual de Maringá, mestre em Geografia pela mesma instituição, especialista em Ensino e Pesquisa na Ciência Geográfica pela Universidade Estadual do Centro-Oeste e graduada em Licenciatura em Geografia pela Universidade Estadual de Maringá. É participante do Grupo de Pesquisa Educação Geográfica e Formação de Professores de Geografia (EDUPROGEO)

Av. Colombo, 5790, Zona 7, CEP: 87020900, Maringá - PR.

E-mail: tais_piresoliveira@ hotmail.com 


\section{Claudivan Sanches Lopes}

Possui pós-doutorado pela Pontifícia Universidade Católica de Goiás, doutorado em Geografia Humana pela Universidade de São Paulo FFLCH/USP, mestrado em Educação pela Universidade Estadual de Maringá e graduação em Geografia pela mesma Universidade. Atualmente é Professor Associado na Universidade Estadual de Maringá (Departamento de Geografia) e do Programa de Pós-Graduação em Geografia (PGE) nesta mesma Universidade. É coordenador do Grupo de Pesquisa Educação Geográfica e Formação de Professores de Geografia (EDUPROGEO).

Av. Colombo, 5790, Zona 7, CEP: 87020900, Maringá - PR.

E-mail: claudivanlopes@gmail.com

Recebido para publicação em setembro de 2018 Aprovado para publicação em fevereiro de 2019 